Etnográfica

Revista do Centro em Rede de Investigação em

Antropologia

vol. 17 (2) | 2013

Vol. $17(2)$

\title{
Christian Hottin (org.), Le patrimoine culturel immatériel: Premières expériences en France
}

\section{Ana Carvalho}

\section{OpenEdition}

\section{Journals}

Edição electrónica

URL: https://journals.openedition.org/etnografica/3179

DOI: 10.4000/etnografica.3179

ISSN: 2182-2891

\section{Editora}

Centro em Rede de Investigação em Antropologia

\section{Edição impressa}

Data de publição: 1 junho 2013

Paginação: 430-432

ISSN: 0873-6561

\section{Refêrencia eletrónica}

Ana Carvalho, «Christian Hottin (org.), Le patrimoine culturel immatériel: Premières expériences en France», Etnográfica [Online], vol. 17 (2) | 2013, posto online no dia 20 junho 2013, consultado o 11 fevereiro 2022. URL: http://journals.openedition.org/etnografica/3179 ; DOI: https://doi.org/10.4000/ etnografica. 3179

Etnográfica is licensed under a Creative Commons Attribution-NonCommercial 4.0 International License. 
apontando caminhos às ciências sociais para ensaiar outros contextos, teorias, questões de pesquisa e metodologias que se afiguram como essenciais.

\section{Christian Hottin (org.)}

\section{LE PATRIMOINE CULTUREL IMMATÉRIEL: PREMIÈRES EXPÉRIENCES EN FRANCE}

Paris, Maison des Cultures du Monde e Babel, 201 1, 364 páginas, ISBN: 978-2-7427-8977-1.

Este livro de bolso insere-se na coleção Internationale de l'imaginaire (n.s., n. ${ }^{\circ}$ 25), dirigida por Chérif Khaznadar, e constitui o terceiro número dedicado ao património cultural imaterial (PCI). O primeiro número - Le patrimoine culturel immatériel: Les enjeux, les problématiques, les pratiques (2004) - constitui uma das primeiras reflexões sobre os contextos, limites e potencialidades da Convenção para a Salvaguarda do Património Cultural Imaterial da UNESCO (2003), e o segundo - Le patrimoine culturel immatériel à la lumière de l'Extrême-Orient" (2009) uma perspetiva sobre as experiências da China, da Coreia e do Japão em matéria de PCI, tidas como políticas-modelo que moldaram o espírito da Convenção de 2003. Por seu turno, este último livro versa sobre as primeiras experiências em França na implementação desta convenção. ${ }^{1}$ Tendo

I Aprovaram a Convenção de 2003148 países, comprovando o sucesso deste normativo (cf. $<$ http://www.unesco.org/eri/la/convention .asp $? \mathrm{KO}=17116 \&$ language $=\mathrm{E}>$, consultado a 30/4/2013).
Joana Azevedo

CIES-IUL, ISCTE - Instituto Universitário

de Lisboa, Portugal

joana.azevedo@iscte.pt

como ponto de partida a narrativa oficial da UNESCO (a França aprovou a convenção em 2006), o livro dá conta, em jeito de balanço, do trabalho desenvolvido sobre esta matéria no âmbito das políticas públicas dos últimos quatro anos.

As contribuições contidas no livro são de profissionais de várias instituições francesas ligadas ao património e de representantes da UNESCO que fazem, assim, parte da comunidade de especialistas que procura encontrar respostas aos desafios lançados pela Convenção de 2003, um normativo que aponta para um conceito mais líquido sobre património, uma perspetiva renovada e dinâmica sobre salvaguarda e um papel mais ativo das comunidades, seja na identificação e reconhecimento, seja na sua implicação no processo de proteção deste património. A tradução destas recomendações implica a revisão do papel das instituições e dos profissionais, um processo ainda recente para muitos países e que este livro procura clarificar, dando a conhecer os esforços realizados pela administração francesa no sentido de adequar as suas políticas e instrumentos às recomendações da Convenção de 2003.

Com efeito, esta convenção tem sido terreno fértil para a discussão sobre o conceito de património e tornou-se também objeto de estudo nos últimos anos, tal como é percetível pelo aparecimento de variadas publicações que atestam pelo menos duas abordagens: uma baseada na 
avaliação e balanço das experiências por parte dos profissionais intervenientes no processo de patrimonialização, como é o caso deste livro, e outra que se posiciona de forma crítica e reflexiva sobre a Convenção de 2003 e o seu impacte, problematizando o fenómeno do património em si mesmo, vinda sobretudo dos antropólogos da academia - veja-se, por exemplo, C. Bortolotto, A. Arnaud e S. Grenet (orgs.), Le patrimoine culturel immatériel: Enjeux d'une nouvelle catégorie, publicado em 2011.

O livro organiza-se em duas partes. Um preâmbulo à primeira parte (por Chérif Khaznadar, Christina Hottin e Sylvie Grenet) serve para contextualizar a Convenção de 2003, a sua retórica e os princípios de atuação subjacentes à criação de uma nova categoria de património - o PCI Ao longo desta primeira parte é explicado como se operacionalizaram as estratégias para a salvaguarda do PCI pelo Ministério da Cultura francês, assentes numa lógica de criação de inventários para identificar o PCI e documentá-lo. Neste âmbito, Sylvie Grenet descreve as linhas operativas de um novo inventário para o património vivo e o processo conducente à recolha de várias bases de dados previamente existentes, no sentido de se fazer um "inventário dos inventários". Ainda nesta linha, Véronique Guinouvés descreve as metodologias seguidas no âmbito do projeto de criação de um portal coletivo sobre património oral que resulta das recolhas de amadores e profissionais no domínio das ciências sociais e humanas ao longo de várias décadas. $\mathrm{O}$ portal pretende dar visibilidade a um extenso arquivo sonoro e audiovisual, em grande medida pouco conhecido e disperso por várias organizações. As iniciativas em torno da acessibilidade a repositórios de informação são hoje uma tendência que tem a ver também com as potencialidades que oferecem as novas tecnologias e a Internet para o património/conhecimento/cultura e que se têm traduzido em muitos projetos de digitalização na Europa e na criação de bases de dados em rede (p. ex. Europeana). Neste sentido, a ênfase atual na valorização do PCI permite, assim, o surgimento de projetos, como é o caso deste portal dedicado ao património oral.

Um aspeto relevante é levantado por Christian Hottin, ao argumentar a distinção entre o património etnológico e o PCI e, por sua vez, o papel atribuído à investigação no contexto do que significa a salvaguarda nos moldes propostos pela convenção. $\mathrm{O}$ autor descreve, grosso modo, a política definida para o património etnológico francês nos últimos trinta anos, fortemente alicerçada no desenvolvimento de investigação científica, para justificar a criação de um inventário para o PCI apoiado em programas de investigação (e através das redes de investigadores e centros de investigação já existentes no âmbito da antropologia), ainda que de acordo com a convenção os inventários sejam acima de tudo um instrumento de reconhecimento e possam não estar vinculados à investigação propriamente dita. Como se pode constatar, no caso francês, a tradição de trabalho com o património etnológico determinou indelevelmente os moldes em que se operacionalizou o inventário, em estreita relação com o desenvolvimento de uma estratégia de investigação e de trabalho de terreno.

Sobre o contexto regional destaca-se o texto de Charles Quimbert, que dá voz ao trabalho desenvolvido na Bretanha e à forma como se foram esboçando os eixos de intervenção com relação a uma política favorável à salvaguarda do PCI, incluindo, ainda, uma abordagem do caso dos ateliês de bordados de Puy-en Velay e Alençon (perspetiva histórica, funcionamento, candidatura à lista representativa).

A segunda parte do livro introduz ao leitor uma outra dimensão da Convenção de 2003, designadamente a inscrição de 
elementos do PCI na categoria de "património da humanidade”. Efetivamente, a convenção prevê dois instrumentos principais - uma lista representativa e uma lista de salvaguarda urgente, não esquecendo uma base de dados de boas práticas, porventura menos conhecida. Além da experiência francesa na preparação de candidaturas (uma dezena de projetos foram submetidos ao Ministério da Cultura), aliás, suficientemente ilustrativa (quem avalia, procedimentos, seleção, critérios, recomendações, prazos, exemplos, etc.), assume particular interesse o balanço que Cécile Duvelle (atual chefe de secção do PCI na UNESCO e secretária da Convenção de 2003) faz da primeira fase de candidaturas às listas, não escondendo as fragilidades e as expetativas defraudadas do processo, nomeadamente a corrida à lista representativa em detrimento da lista de salvaguarda urgente, bem como a marginalidade do catálogo de boas práticas.
Ainda que não perca de vista o sentido crítico (p. ex. no texto de Khérif Khaznadar), o livro assume, em grande medida, um tom descritivo e, nalgumas situações, quase operativo. Os anexos são disso reflexo e incluem exemplos de fichas de inventário e candidaturas, formulários, calendarização, etc. No entanto, tal pode ser de grande utilidade para todos aqueles que trabalham em projetos de valorização do PCI e na definição de políticas da sua salvaguarda nas instituições culturais, seguindo o discurso oficial. Além disso, atendendo ao caráter experimental e recente destas políticas, publicações como esta são um contributo válido para relativizar criticamente as várias interpretações de que a Convenção de 2003 é objeto.

Ana Carvalho

CIDEHUS, Universidade de Évora, Portugal ana.alexandra.carvalho@gmail.com 